\title{
As Lisboas de duas pessoas *
}

\author{
Gilda Santos \\ (Universidade Federal do Rio de Janeiro, \\ Real Gabinete Português de Leitura)
}

\section{RESUMO}

Primeiramente, examinam-se aqui as motivações que levaram Fernando Pessoa a escrever o guia Lisboa: o que o turista deve ver, algumas características do livro, diálogos possíveis deste com outros textos pessoanos e a relação do autor com a cidade em que nasceu. Depois, comenta-se o diário de viagem de Cleonice Berardinelli, renomada estudiosa de Pessoa, em sua primeira visita a Lisboa e seu especial "encontro" com o poeta dos heterônimos.

PALAVRAS-CHAVE: Fernando Pessoa, Lisboa: o que o turista deve ver, Cleonice Berardinelli

\section{ABSTRACT}

First of all, this paper deals with the motivations that led Fernando Pessoa to write the guide Lisbon: what the tourist should see, some characteristics of the book, possible interactions between its text and other "pessoanos" writings, as well as the author 's relationship with the city in which he was born. Afterwards, there are comments on the voyage diary of Cleonice Berardinelli, renowned scholar of Pessoa, in her first visit to Lisbon and her particular "encounter" with the poet of the heteronymous.

KEYWORDS: Fernando Pessoa, Lisbon: what the tourist should see, Cleonice Berardinelli 


\section{Pessoa 1}

Neste meu título evoco As Lisboas de Pessoa, que nomeia uma exposição e, simultaneamente, uma publicação exemplar, que divulgou em várias línguas a relação intensa do poeta com a cidade eleita - e habitada quase que por toda a vida, não fosse a imposta permanência em Durban. Como sabemos, são sobretudo o cosmopolita engenheiro Álvaro de Campos e o deambulante pensador Bernardo Soares os heterônimos que mais fornecem legendas às várias faces da cidade de Ulisses, que o singular e plural Pessoa demonstrava conhecer bem, apesar de nem sempre ser-lhe fácil o cingi-la. Nesse rastro, nas várias latitudes onde há estudos lusófonos, sucedem-se textos críticos, livros fartamente ilustrados e mostras criativas a vincar a presença urbana nos papéis provindos da inesgotável arca. À guisa de exemplo, note-se que não cessam as edições de Lisboa nos passos de Pessoa, de Marina Tavares Dias, e que, neste 2008, a Casa Fernando Pessoa abriga, até 26 de setembro, a exposição intitulada Os Lugares de Pessoa, assinalando os 120 anos de seu nascimento.

Mas, em meio às páginas literárias - lidas, relidas, discutidas e disputadas -, foi encontrada em 1988 uma obra considerada como pronta para ser impressa e que prima pelo pragmatismo: Lisboa: o que o turista deve ver. Isso mesmo: um guia turístico. Aliás, originalmente datilografado em inglês Lisbon: What the tourist should see.

A consciência clara de que tudo - tudo mesmo - que Pessoa escreveu constitui cânone literário, digno, portanto, de estudo acadêmico, só a adquiri quando, há uns anos, vi as suas Cartas de Amor - e só elas, sem qualquer outro texto de sua autoria - listadas no edital de um concurso público para Professor Adjunto de Literatura Portuguesa na Universidade Federal de Minas Gerais. Embora "todas as cartas de amor sejam ridículas", como Álvaro de Campos nos ensinou, e seu criador bem demonstrou... Desde então, nada mais me surpreendeu, e não me surpreenderei se, amanhã, até os recibos comerciais apenas assinados por Pessoa vierem a ser submetidos a doutíssimas análises. Posto isto, espero também não surpreender quem me lê, ao dizer que vou agora tratar desse guia turístico de Lisboa, de escrita estimada em novembro/dezembro de 1925, descoberto no espólio exatamente no ano do centenário de nascimento de seu autor.

Logo traduzido para o português e publicado desde 1992 em edição bilíngue, é hoje o livro mais vendido aos estrangeiros na emblemática casa da Rua Coelho da Rocha. Com traduções em mais uns cinco ou seis idiomas, já mereceu comentários atentos de nomes respeitáveis como José-Augusto França, Robert Bréchon e Fernando J. B. Martinho, entre outros ${ }^{2}$. E, no Brasil, foi corpus de uma dissertação de Mestrado, defendida na USP em 2006.

Tendo em mente livros como Lisboa, Livro de Bordo de José Cardoso Pires, ou Meu Porto de Mário Cláudio, ou ainda o poema-paradigma "O Sentimento dum Ocidental" de Cesário, ou mesmo o segmento "lisboeta" de Viagem a Portugal de Saramago, a suspeita de que as páginas de Lisboa: o que o turista deve ver poderiam revelar ao leitor muito de uma relação - digamos - lírico-afetiva do escritor com seus espaços de memória, desfaz-se rapidamente, quer pela objetividade descritiva do discurso, quer pela falta de referências indissociáveis da figura do poeta, como os cafés. E embora, aqui e ali, encontremos tênues ecos de alguns versos célebres 
daquele "engenheiro formado em Glasgow", ou de umas poucas frases daquele "ajudante de guarda-livros", tendemos logo a concordar com a avaliação, talvez excessivamente dura, de Bréchon:

Quando apareceu o pequeno guia de Lisboa redigido em inglês [...] não quis acreditar que tivesse sido ele o seu autor. Neste texto pobre, sem emoção, sem poesia, sem humor, não existe qualquer traço do génio que normalmente reconheço em tudo que ele escreveu, qualquer que seja a sua máscara. (Bréchon, 1999, p. 47).

Avaliação que repercute num atilado comentário "blogueiro" a propósito da primeira edição brasileira, pela Companhia das Letras:

Ao leitor, resta pouco mais que a sensação curiosa de empreender um longo passeio imaginário pela cidade na companhia de um gênio que insiste em assumir uma aparência ordinária. Acaba sendo isso, afinal, o que o livro tem de mais interessante: a demonstração de que, entre tantas personas e heterônimos, Fernando Pessoa era capaz até, se quisesse, de se transformar num escritor convencional. (Conde, 2008)

Ora, se não é no diálogo explícito e constante com a sua conhecida obra, ou mesmo com sua biografia, que podemos encontrar uma justificativa para o livro, há que buscar alhures pistas para a performance deste heterônimo investido do papel de cicerone. Nessa demanda, percorramos, pois, os itinerários do texto.

Pressupondo que o turista chega por mar, é com uma visão panorâmica da cidade, tomada do Tejo, que se abre este guia prático.

Sobre sete colinas, que são outros tantos pontos de observação de onde se podem desfrutar magníficos panoramas, espalha-se a vasta, irregular e multicolorida massa de casas que constitui Lisboa.

Para o viajante que chega por mar, Lisboa, vista assim de longe, ergue-se como uma bela visão de sonho, sobressaindo contra o azul vivo do céu, que o sol anima. E as cúpulas, os monumentos, o velho castelo elevam-se acima da massa das casas, como arautos distantes deste delicioso lugar, desta abençoada região.

O espanto do turista começa quando o barco se aproxima da barra e [...] lhe aparece o baluarte que é a Torre de Belém, como um exemplar magnífico da arquitetura militar do século XVI, em estilo romano-gótico-mourisco. À medida que o barco avança, o rio torna-se mais estreito, para logo alargar de novo, formando um dos mais largos portos naturais do mundo, podendo nele ancorar as maiores frotas. Então, à esquerda, as massas de casas agrupam-se vivamente como cachos sobre as colinas. E aí temos Lisboa. (p.31)

Depois, saindo do cais, e prevendo o uso de um automóvel - talvez aquele fiel Chevrolet de Álvaro de Campos -, delineia roteiros até hoje factíveis, que destacam os ex-libris de Lisboa pelos diferentes bairros, inclusive em zonas à época mais afastadas, como Benfica e Amadora. A chegada a Sintra, via Queluz, marca o fim da sua proposta de circuito. Mas antes, curiosamente, numa espécie de apêndice, apresenta-nos todos os jornais em circulação na cidade, a indiciar, decerto, a efervescência de ideias típica de uma metrópole, o que condiz com a imagem que intenta fixar. 
Hoje, à distância de setenta e poucos anos, surpreende constatar que as alterações urbanas não foram tantas assim. Excetuando a trasladação dos restos mortais de dignitários e escritores do Mosteiro dos Jerônimos para o Panteão Nacional, ou ainda a grande transformação operada no Campo Grande (que, reiterando inúmeras páginas oitocentistas, perdeu todo bucolismo aí descrito; mas propiciou a mudança para lá, em melhores instalações, da Biblioteca Nacional e da Torre do Tombo, também visitadas pelo guia em seus antigos espaços), pouco mais do que lemos ficou desatualizado.

Como de praxe nesses roteiros de viagem, ao lado de rápidas informações quanto à época e constituição dos objetos focalizados, encontramos, sempre que cabível, informações práticas sobre os horários de visita e custo dos ingressos. No entanto, diferentemente do habitual, nesta outra "Lisbon revisited" há que sublinhar algumas peculiaridades que parecem pressupor um turista mais curioso e sensível à percepção de valores históricos, artísticos, culturais.

A primeira refere-se à insistência para que esse turista/leitor observe obras de estatuária espalhadas pela cidade, desde as mais singelas, em que poucos repararão, como aquela dedicada a Pinheiro Chagas na Avenida da Liberdade (p. 43), até conjuntos alegóricos monumentais como o dos Restauradores (p.43), o do Marquês de Pombal (p. 45) e o da Guerra Peninsular (p. 47), os dois últimos ainda em construção na altura. E o destaque, algo incomum, dado a esses marcos proeminentes essencialmente urbanos completa-se com minúcias quanto às datas, às suas medidas, aos materiais utilizados, aos artistas envolvidos, à "leitura" de sua composição...

Esta mesma vontade de tudo apreender em pormenor reflete-se ainda na descrição de interiores onde nos faz penetrar, como museus, palácios, igrejas e bibliotecas, obrigando-nos a deter o olhar sobre os quadros, os estofos, as alfaias, os livros...

Nota-se ainda no volume, como única ruptura ao despojamento retórico que o caracteriza, o uso contínuo de formas adverbiais de intensidade acompanhando os pontos destacados, como a nos convencer, em tom publicitário, de que só uma Lisboa em superlativo desfila diante de nós, excedendo largamente congêneres "do estrangeiro". Assim, "o Coliseu dos Recreios [é] um dos maiores teatros e circos de toda a Europa" (p. 65); no museu da Igreja de São Roque, há alfaias "num esplendor total de obras de metal precioso que nenhum outro país pode orgulhar-se de possuir" (p. 75); o Aqueduto das Águas Livres é "um verdadeiro monumento nacional, e talvez o mais notável do seu gênero na Europa, sempre chamou muito a atenção dos estrangeiros, tendo sempre ouvido deles um louvor unânime inteiramente merecido" (p. 83); a Academia de Ciências de Lisboa possui "uma das mais belas salas do género em toda a Europa" (p. 115). E um exemplo espantoso de detalhismo: no "Clube dos Restauradores Maxim's", atual Palácio Foz, "Este admirável corrimão foi executado em Paris e custou então cerca de 9.000 libras. É um espécime mais sumptuoso que o do Castelo de Chantilly, dos Duques de Aumale, que é tido como o mais belo do mundo" (p. 109). De fato, afirmativas surpreendentes, uma vez que provindas de quem nunca saiu de Portugal, e de Lisboa só viajou até Portalegre...

De posse desses dados, como situar este manual de perambulações olissiponenses, no conjunto da obra pessoana? Consta que a resposta localiza-se em outros papéis encontrados pela mesma equipa que "descobriu" o volume na "arca": muito incomodado com o desconhecimento sobre Portugal que comprovou entre seus colegas em Durban, pouco depois de seu regresso a Lisboa 
(em 1905) Pessoa propõe-se a produzir textos voltados para uma valorização de sua terra, com cunho propagandístico explícito. Não é por outro motivo que delineia o projeto All about Portugal, visando a uma orquestrada propaganda portuguesa além-fronteiras, do qual este guia constituiria um capítulo:

Chamava-se Cosmopolis a firma que o poeta idealizou para realizar esse objectivo, que contemplava a criação de um semanário português para ser distribuído no estrangeiro e de um outro para consumo interno, "A Semana", que inserisse notícias cosmopolitas, a edição de postais ilustrados sobre Portugal e um guia de Lisboa. (JL, 1992, p.8)

Ao valorizar o patrimônio cultural português, tal como o agiganta nas páginas citadas, almeja acabar com aquilo que chama de "descategorização européia" e "descategorização civilizacional" que percebe nesse Portugal invisível aos olhos dos estrangeiros.

Destarte, abandonando tanto a cidade esgarçada do flâneur Bernardo Soares, quanto a moderna metrópole vivida tão doridamente - "Cidade da minha infância pavorosamente perdida" "3 -, por Álvaro de Campos, para mapeá-la com objetividade jamais encontrada em sua obra literária, Pessoa parece atender ao imperativo de uma missão que a si próprio impôs: somente a determinação em revelar Lisboa com a autoridade de um nativo culto, comprometido com valores específicos, justificaria livro de tal modo calcado no cartográfico, cronológico e factual. Até porque, desde 1898, os conceituados e minuciosos guias Baedeker ${ }^{4}$ contemplavam Portugal e Espanha (Baedeker's Handbook for Travellers in Spain and Portugal) em um volume repleto de mapas, que rapidamente atingiu cinco edições. E, reza a tradição, ninguém menos do que o "Kaiser" Guilherme I declarara: "Reis e governos podem errar, mas nunca o Sr. Baedeker" ${ }^{5}$...

Ora, projeto de dignificação nacionalista similar repercute em Mensagem "a mais portuguesa das obras de Pessoa", nas palavras de Cleonice Berardinelli bem como nos poemas "Quinto Império" e "À memória do Presidente-Rei Sidônio Pais" - textos onde fica claro o propósito de superação do sentido de decadência que traumatizava Portugal desde Alcácer-Quibir e se agudizara mais recentemente com o Ultimatum britânico. Assim, não é difícil perceber a consonância entre trechos do guia turístico e versos dos poemas referidos. Por exemplo: alguns dos protagonistas escolhidos pelo poeta para comporem sua particular galeria nacional, que se percorre em Mensagem, já foram comparados a estátuas (nomeadamente aqueles que compõem o Timbre do Brasão, "O infante D. Henrique", "D. João, o Segundo" e "Affonso de Albuquerque"), tal como as que se encontram a pontilhar os percursos a que nos conduz este cicerone.

Outro exemplo: nesse travelling por Lisboa, apesar da rapidez com que tantas imagens desfilam diante de nós, o mesmo cicerone força-nos por três vezes a cruzar com Sidônio Pais, dedicando-lhe muito mais atenção do que a vários outros chefes políticos, e mais linhas do que seria previsível em livro de tão escassas páginas. Em São Roque, obriga-nos a

reparar nos dois grandes tocheiros de prata cinzelada, trabalho do famoso Giuseppe Gagliardi, que só uma vez deixaram o museu, para figurarem nas exéquias do Dr. Sidónio Pais, o infortunado Presidente da República que foi assassinado no piso superior da 
Estação do Rossio, na noite de 14 de Dezembro de 1919, quando ia tomar o expresso do Norte. Cada tocheiro pesa cerca de 380 quilos e mede 2,85 metros de altura (p. 75);

no Parque Eduardo VII sublinha: "Foi nestes terrenos que, em 5 de dezembro de 1917, Sidónio Pais se entrincheirou, com vários regimentos da guarnição de Lisboa, e derrotou o governo ‘democrático’ em que Norton de Matos era Ministro da Guerra” (p. 81); e no Mosteiro dos Jerônimos,

Neste sítio foi posto, em 21 de Dezembro de 1918, o corpo do Dr. Sidónio Pais, Presidente da República, que foi acompanhado até ao mosteiro por uma multidão de muitos milhares de pessoas, numa tocante e sincera manifestação de pesar. O corpo foi depois transferido para a Capela do Baptismo e mais tarde para o quarto túmulo a contar da cruz, onde ainda permanece (p.93)

Posto isto, começamos a desconfiar que, para lá do bom roteiro proposto por alguém que ocupou nada menos do que dezesseis moradas em Lisboa, e da exaltação do apreciável patrimônio cultural inventariado, há mais motivos para se ler com atenção este guia pessoal e pessoano.

\section{Pessoa 2}

Em março de 1959, a bordo do paquete italiano Conte Grande, chega a Lisboa, pela primeira vez, a professora brasileira que acabara de defender sua tese de Doutorado sobre Fernando Pessoa.

E foi sob o signo de Pessoa que os preparativos começaram a tomar corpo. Escreve ela, numa espécie de diário, construído com despretensiosas cartascirculares que enviava à família ${ }^{6}$ :

No princípio era o sonho... Mas agora já começou a ser realidade... Agora, agora, não: desde o dia em que fomos à Polvani e vi, no mapa da Europa, os caminhos que iríamos seguir [...]. Desde então a viagem começou a ser real (esta frase é quase igual a uma de Álvaro de Campos: "a lua começa a ser real” (!)). Será que eu não posso dizer, ver ou pensar, sem que Pessoa se intrometa?

E eis como o sonho se delineia em paisagem contemplada:

Entramos no Tejo de manhã bem cedo. Fazia um friozinho cortante, mas subimos ao convés superior para dar bom dia a Lisboa. O rio é larguíssimo - 300 a $400 \mathrm{~m}$ - e suas águas continuam em colorido as do mar. A margem direita de quem entra é a mais desabitada, mas à esquerda logo se vêem os bairros dos arredores da capital, à beira-rio e subindo em graciosas colinas. [...] Entre um amontoado e outro de casas, um tufo de pinheiros bem verdes. Logo divisei a Torre de Belém, entrando na água como um barco que vai partir". 
É óbvio que Cleonice Berardinelli não lera os encômios a Lisboa daquele ainda desconhecido heterônimo-cicerone, mas, pela clara sintonia, é como se os tivesse lido...

A minha lusofilia quase empalidece diante da admiração de meu marido. De fato, Lisboa é uma cidade engraçada, como se diz aqui. Há do velho e do novo, misturados ou apartados: ruelas estreitas e tortuosas, em ladeiras íngremes e suaves, com sobrados de frontaria de azulejos de cores e desenhos variados, sacadinhas de grade (onde sempre há cordas com roupas a secar); becos estreitíssimos, que não recebem o sol, cujas paredes podem quase ser tocadas ao mesmo tempo por um homem de braços abertos, calçadas de pedras irregulares, escuras como as de Ouro Preto - é a cidade velha; avenidas largas, arborizadas, com praças arredondadas, sucedendo-se umas às outras, todas ladeadas de edifícios semelhantes, com a mesma altura (cinco ou seis andares), bem afastados - é a cidade nova. Têm apenas uma coisa em comum: o colorido. As casas são verdes, azuis, cor-de-rosa escuro, meio cor de tijolo. A avenida Sidônio Pais é quase toda desta cor. A sensação que a cidade transmite é de calma, ordem, limpeza

Depois desse prólogo, sucedem-se as visitas aos monumentos icônicos de Lisboa e arredores, todos aquinhoados com comentários que deixariam feliz, tanto pela seleção em si, quanto pelo tom entusiasta, o autor daquele vademecum: a Baixa, o Convento do Carmo, o Castelo de S. Jorge, Alfama, S.Vicente de Fora, a Feira da Ladra, o Bairro Alto (com direito a Casa de Fados), o Palácio de São Bento, a Torre do Tombo, o Museu de Arte Antiga, os Jerônimos (ainda com o túmulo de Sidônio Pais...), a Torre de Belém, o Museu dos Coches, Queluz, Sintra, Cascais, Estoril, Mafra...

Mas, Lisboa, cidade na qual Pessoa dizia estar fincado como um poste, por si só propicia novas formas de apreensão do heteronímico poeta. Assim, em resgate do biográfico, Cleonice busca o espaço-berço:

No dia 20, 6a feira, o programa era começar indo ao largo de S. Carlos, para fotografar a casa em que nasceu Pessoa, um edifício de 5 andares (sem elevador), onde a família habitava o $4^{\circ}$. [...] Álvaro [marido] fotografou o prédio e especialmente a lápide que há pouco ali puseram [..] No dia da inauguração falou Vitorino Nemésio. Era um dia feio, chuvoso, e contou-me a Maria Aliete que, antes que alguém corresse o pano que cobria a inscrição, fê-lo o vento. É uma curiosa coincidência, tratando-se de um poeta que dizia: "Stou prêso ao meu pensamento/ Como o vento prêso ao ar".

Seguindo-se a rua Serpa Pinto em direção à rua Garrett, mesmo à esquina desta, está a Igreja dos Mártires [...] Da sua casa, o poeta ouvia os sinos da igreja, aqueles mesmos de que diz, transmudando, "ó sino da minha aldeia..."

E também visita Almada Negreiros no seu atelier, encantando-se com esse parceiro de Pessoa em aventuras modernistas: 
Homem de sessenta e tal anos, foi o grande artista plástico do "Orpheu". [...] Recebeu-nos muito bem, mostrou-nos coisas bonitas que está fazendo ou já fez [...] entre as já feitas, reproduções do retrato mural do Pessoa que está no café que ele freqüentava - Irmãos Unidos - na parede acima da mesa onde costumava ficar. [...] Quando saímos, o Professor Cidade resolveu levar-nos ao café, que fica mesmo no Rossio, para mostrar-me a pintura. Saímos a pé e tomamos um cafezinho quente e gostoso, a olhar (eu, pelo menos) para o Poeta. É um retrato excepcionalmente feliz na sua realização. O Almada fê-lo de memória, há somente cinco anos. O poeta está banhado por uma luz que vem do alto e lhe ilumina o rosto fino, as mãos "longas e lindas" (diria o Sá-Carneiro) e lhe dá um ar da mais alta espiritualidade.

Em âmbito acadêmico alargado, Cleonice tanto registra seus encontros com vários estudiosos de Pessoa - Jacinto do Prado Coelho, Joel Serrão e Jorge de Sena -, como o sucesso de uma aula que ministra na Faculdade de Letras:

Às 10h20m, mais ou menos, diante de um enorme anfiteatro com cerca de trezentos alunos e os professores Hernani Cidade (e Sra.), Jacinto do Prado Coelho (e Sra.), Lindley Cintra, Serafim da Silva Neto (Sra. e filha), Delfim Santos, Maria de Lourdes Belchior Pontes, foi iniciada a aula sobre Fernando Pessoa, precedida de uma gentilíssima apresentação do Professor Jacinto do Prado Coelho, titular da cadeira de Literatura Portuguesa. Ao terminar, uma estrepitosa salva de palmas que o marido diz ter sido a maior que ele já ouviu (diz ele, não eu...). Os professores portugueses cumprimentaram vivamente (e acho que sinceramente) a professora brasileira...

Por fim, nesse assinalado março de 1959, já prestes a partir de Portugal, Cleonice faz emocionada visita à famosa, à mítica arca, sem adivinhar o que lhe reservaria o futuro de convívio longo, estreito e profundo com os autógrafos pessoanos que pela primeira vez via e tocava.

Num quinto andar da Avenida da República 48, mora o Cel. Caetano Dias, com sua mulher, D. Henriqueta Rosa, irmã caçula do poeta. Recebeu-nos ela - uma bonita senhora de cinqüenta e tantos - e a filha. Muito amáveis, introduziram-nos numa salinha de visitas onde estão, num armário de vidro, os livros dele. Mas eu não queria ver livros e sim os seus papéis. Estão noutra salinha ao lado da primeira, guardados em uma mala baixa de madeira, de cerca de 1,20m de comprimento, e numa outra malinha menor, desse tipo ordinário, com travessas de pau.

É um mundo o que lá está ainda por publicar. Não vi senão umas poucas coisas, mas o que mais me impressionou foi o Livro do Desassossego, espécie de diário, cuja prosa tem belezas que eu não suspeitava. 
Pela quantidade de papeluchos - beiradas de jornal, contas, notas em que escrevia, vê-se quanto tinha dentro de si e que necessidade sentia de escrever sempre, sempre... Foi um grande momento para mim, mas, como não pôde ser mais que um momento, um suplício de Tântalo...

Pois é... Só um momento... Que suplício!... Coitadinha!

* Versão revista da comunicação apresentada no Colóquio Meio Século em Pessoa, promovido pela Cátedra Jorge de Sena/UFRJ em homenagem aos 50 anos de Doutoramento de Cleonice Berardinelli, realizado na Faculdade de Letras/UFRJ nos dias 17 e 18 de junho de 2008.

\section{NOTAS}

1. Da edição indicada nas Referências bibliográficas são todas as citações incluídas no texto, seguidas dos números das páginas entre parêntesis.

2. Ver mais indicações na portentosa Pessoana de José Blanco.

3. "Lisbon Revisited" -1926

4. Karl Baedeker é o fundador de uma editora alemã que, a partir de 1827, editou guias de viagem que, por serem considerados os pioneiros no gênero, se tornaram referência mundial, passando logo a designar comumente todos os guias turísticos, mesmo de outras editoras (metonímia em que inventor e invento se confundem, tal como Gillette e sua lâmina...). Muito prestigiados e de tal modo precisos, consta que, durante a Segunda Guerra Mundial, a Alemanha tomou como referência o Baedeker of Great Britain para uma série de ataques aéreos em cidades inglesas, que, então, ficaram conhecidos como "Baedeker blitz" ou "Baedeker raids". Destruídos em 1943 os arquivos da editora, em 1948 o bisneto do fundador retomou os negócios da família e os guias, constantemente atualizados, existem até hoje. Ver www.baedeker.com

5. Ver www.espritdescalier.de/blog/pt/tag/vergeler/

6. Sob o título "Relances de uma descoberta de Portugal", na revista Metamorfoses $\mathrm{n}^{\circ}$ 1, p. 201-207, editei alguns trechos desse "diário" ainda inédito na totalidade.

\section{REFERÊNCIAS BIBLIOGRÁFICAS}

BERARDINELlI, Cleonice, ed. Poemas de Álvaro de Campos. Rio de Janeiro: Nova Fronteira, 1999.

BLANCO, José. Pessoana - Bibliografia passiva, selectiva e temática. Lisboa: Assírio e Alvim, 2008. 2 v.

BRÉCHON, Robert. Pessoa e Lisboa. Tabacaria, Lisboa, no7, p. 47-53, mai. 1999.

CLÁUdIO, Mário. Meu Porto. Lisboa: D. Quixote, 2001.

CONDE, Miguel. O estranho guia turístico de Fernando Pessoa. Texto postado em 08/5/2008, acessível em http://oglobo.globo.com/blogs/prosa/post.asp?t=o-estranho-guiaturistico-de-fernando-pessoa\&cod_Post $=101510 \& \mathrm{a}=96$

DIAS, Marina Tavares. Lisboa nos passos de Pessoa. 2 ed. Lisboa: Quimera, 2002. (Ed. bilíngue port./ing.) 
FAZZOLARI, Davi. Olhares sobre Lisboa: o Livro do Desassossego' e 'O que o turista deve ver', São Paulo: FFLCH-USP, 2006. (Dissertação de Mestrado)

FRANÇA, José Augusto. Pessoa, Lisboa e a geração modernista. As Lisboas de Pessoa. Lisboa: Institut d'Edicions de la Diputació de Barcelona e Centre de Cultura Contemporánia de Barcelona, p. 139-144, 1997.

JL- Jornal de Letras, Artes e Idéias. Lisboa, 3/11/1992.

MARTINHO, Fernando J.B. Lisboa pela mão de Pessoa. Colóquio Letras. Lisboa, $\mathrm{n}^{\circ}$ 142, p. 232, out./dez.1996.

METAMORFOSES. Rio de Janeiro/Lisboa: Cátedra Jorge de Sena/Ed. Cosmos, $\mathrm{n}^{\mathrm{o}} 1,2000$.

PESSOA, Fernando. Lisboa: o que o turista deve ver/ What the tourist should see. 4 ed. Lisboa: Livros Horizonte, 2007.

PIRES, José Cardoso. Lisboa. Livro de Bordo. Lisboa: d. Quixote, 1997.

SARAMAGO, José. Viagem a Portugal. Lisboa: Caminho, s/d 